\title{
Parental support and monitoring as associated with adolescent alcohol and tobacco use by gender and age
}

\author{
Rosalina Mills ${ }^{1 *}$, Michael J. Mann², Megan L. Smith² and Alfgeir L. Kristjansson ${ }^{1}$
}

\begin{abstract}
Background: Parental support (PS) and parental monitoring (PM) are known protective factors against adolescent substance use (SU). However, little is known about whether PS and PM may affect SU outcomes differently by gender and age. This study examined the relationship between PS and PM and adolescent SU, specifically alcohol and tobacco use, stratified by gender and age group.

Methods: Middle and high school students ( $n=2351$, 48.5\% Female) completed surveys of self-reported SU, perceived PS and PM, and socioeconomic background. Age group was defined dichotomously as grade 7-8 Middle school and grade 9-10 High school students. PS and PM were each measured using previously validated tools. SU was measured by lifetime and past 30 days cigarette/alcohol use. One-way ANOVA and binary logistic regression models were completed. Odds ratios and means were reported.

Results: PS and PM were significantly and negatively related to all outcome variables regardless of gender and age group. Mean differences in PS and PM were insignificant between age groups. Between genders, PM scores were significantly higher for girls (14.05) compared to boys (13.48) $(p<0.01)$. Odds Ratios of all four SU types (for alcohol and tobacco use) increased with higher age group, with ORs ranging from 1.45-2.61 ( $p<.05)$.

Conclusions: PS and PM were protective against SU for all participants, consistent with previous literature. Girls reported greater parental monitoring than boys, irrespective of age-group. While girls experienced higher levels of monitoring, they did not report lower SU than boys. This suggests that monitoring girls more closely than boys appears unnecessary in preventing adolescent SU. Finally, PS was a more significant factor in preventing SU for older adolescents (high school aged group) than for younger adolescents, irrespective of gender suggesting that PS may be more impactful and important as adolescents age. As children mature, particularly from middle school to high school, PS may play a larger role in preventing SU for older adolescents compared to younger ones.
\end{abstract}

Keywords: Parental support, Parental monitoring, Adolescent substance use, Appalachia

\footnotetext{
* Correspondence: rgm0014@mix.wvu.edu

${ }^{1}$ School of Public Health, West Virginia University, Morgantown, USA

Full list of author information is available at the end of the article
}

C C The Author(s). 2021 Open Access This article is licensed under a Creative Commons Attribution 4.0 International License, which permits use, sharing, adaptation, distribution and reproduction in any medium or format, as long as you give appropriate credit to the original author(s) and the source, provide a link to the Creative Commons licence, and indicate if changes were made. The images or other third party material in this article are included in the article's Creative Commons licence, unless indicated otherwise in a credit line to the material. If material is not included in the article's Creative Commons licence and your intended use is not permitted by statutory regulation or exceeds the permitted use, you will need to obtain permission directly from the copyright holder. To view a copy of this licence, visit http://creativecommons.org/licenses/by/4.0/. The Creative Commons Public Domain Dedication waiver (http://creativecommons.org/publicdomain/zero/1.0/) applies to the data made available in this article, unless otherwise stated in a credit line to the data. 


\section{Introduction}

Parental support and monitoring have emerged as two important tools in efforts to reduce adolescent substance use and abuse [1-5]. Although the general value of these tools has been well supported, questions remain about how these tools might apply differently to adolescents of varying ages and genders in a manner that further enhances their effectiveness. Understanding how to use parental support and monitoring in an increasingly refined and targeted manner, to prevent adolescent use of substances such as tobacco (smoking or vaping), represents an especially important opportunity to strengthen primary prevention efforts. Therefore, this study examines the associations between parental support, parental monitoring, and adolescent substance use and whether these associations differ by gender and age group among middle and high school students. Findings may provide new evidence about how to best use parental support and monitoring to prevent adolescent use of substances in order to reduce the risk of misuse, abuse or addiction in the future.

Previous research on parental support and monitoring have provided clear definitions of each concept, presented examples of effective target behaviors, and identified some general benefits of these tools when they are used to prevent adolescent substance use and abuse. A brief summary of these findings includes the following core concepts.

\section{Parental support}

Parental support has been defined as "parental behaviors toward the child, such as praising, encouraging and giving physical affection, which indicate to the child that he or she is accepted and loved" [6]. In practice, parents with high parental support will demonstrate several qualities such as caring and warmth, willingness to provide advice, and having open discussions with their children [7]. Existing narratives show that children with low parental support often display negative emotions, [8] lack the ability to cope with stress, and more often engage in substance use [9].

Studies among adolescents have identified parental support as a protective factor for multiple outcomes such as alcohol use and other substance use, [10] depression, and anxiety [11, 12]. Parental support, such as having parents that listen, and ease of access to emotional support, is a protective factor against adolescent anxiety, [13] and is inversely related to various forms of substance use [2, 10, 14-17]. Conversely, just as high parental support is a protective factor for substance use, low parental support has been found to be associated with greater levels of substance use $[12,18]$.

\section{Parental monitoring}

Similar to parental support, parental monitoring-tracking children's whereabouts and activities-is also a known protective factor against alcohol consumption and other substance use among adolescents [1, 11, 19]. Parental Monitoring differs from Parental Support, in that monitoring pertains to parents' knowledge of a child's whereabouts (tracking and surveillance), while parental support pertains to emotional availability and presence [20].

Parental monitoring has been found to delay alcohol initiation in adolescents, as well as to reduce levels of later drinking [21, 22]. Lack of parental monitoring has been associated with an increased risk of engagement in alcohol use among adolescents [5, 23]. On a related note, high parental monitoring has been associated with improved health-related outcomes in adolescents; such as better mental well-being and less delinquency [24]; improved medication adherence [25]; and reduced substance use and substance use intentions among adolescents, $[1,23,26]$ all of which are positively related to substance use.

\section{The potential benefits of stratifying by gender and age group}

Previous systematic and meta-analytic research has established the effectiveness of parental monitoring and support at reducing overall adolescent substance use [27-29]. However, there are reasons to believe that parental support and monitoring may be more or less effective based on a young person's gender or age group. While parental support and parental monitoring have been studied across multiple populations, comprehensive investigations by gender and age have been rare thus far. Studies that have examined these differences have shown inconsistent results. To date, no study has aimed to include both gender differences and age-related differences in the same model.

\section{Gender}

It is no secret that boys and girls are raised and socialized quite differently from each other, around the world and in the U.S. [30-32] In most familial settings, girls are generally encouraged to be more submissive, demonstrate more caution, and generally have less independence [33]. Boys, contrarily, are encouraged to be more independent, take more risks, and are often monitored less than their female counterparts [34, 35]. This difference in socialization and nurturing is evident in the levels of parental monitoring and support we see in boys and girls. Girls are generally monitored more closely by their parents and guardians than boys, and report higher parental support [36]. However, it is unclear if this 
additional monitoring among young women yields additional reductions in substance use.

While parental support and monitoring have generally been found to be negatively associated with adolescent substance use, stratifying the analyses by gender has produced largely inconclusive results thus far. Several studies investigating the relationship between parental support and monitoring with adolescent substance use have shown no significant differences between males and females. In those studies, greater parental support and parental monitoring were found to predict lower lifetime substance use and reduced recent substance use for both genders and no gender differences were observed [37, 38]. However, other studies have suggested that young women may benefit from higher parental support and monitoring as they reported lower levels of alcohol, cigarette and marijuana use [5, 38, 39]. Additionally, other studies have found that parental support and monitoring have larger impacts on reducing substance use among males. In middle schoolers, some evidence has shown that increased parental support is associated with decreased alcohol consumption among boys, yet found no such relationship among girls [40]. Similarly, for parental monitoring, some studies have shown that increased parental monitoring is associated with less alcohol or tobacco use among boys, but not among girls $[39,41]$. Thus, findings seem incomplete regarding potential gender differences across parental monitoring and support.

\section{Age group}

It has been well-documented that alcohol and/or other substance use in adolescence increases the likelihood of alcohol and substance use disorders later in life, and that there are benefits associated with delaying the onset of adolescent substance use [42, 43]. However, not much is currently known about whether or not parental support and monitoring may impact younger and older adolescents differently. Very few studies have stratified by age groups in their analyses, and many well-done studies did not stratify by age even when there was an opportunity to do so $[1,44]$. The few studies that have examined adolescent substance use by age group differences have been largely inconclusive. Some found no age-related differences, [45] while others found some age-related differences but did not investigate parental support or monitoring separately [46]. Likewise, studies stratifying age by grade level, examining younger and older adolescents, found that parental involvement was a protective factor against substance use for all grades, but also did not examine differences in parental involvement based on support and monitoring [47].
In sum, very few studies have examined whether parental support and monitoring differ by gender and age group in their relationship with adolescent substance use, and no study has simultaneously examined these relationships in one and the same model. Given how differently boys and girls are socialized in the US and developmental differences between younger and older adolescents, it is important to measure the differences in support and monitoring each group receives and to learn more about how these strategies may effectively prevent substance use. The current study will address this gap in the prevention research by collecting data from a large sample of middle and high school-aged girls and boys and analyzing differences in the associations between parental support and monitoring as protective factors against substance use as stratified by age group and gender.

\section{Methods \\ Participants}

This study is part of a perennial community health promotion project titled "Integrated Community Engagement (ICE) Collaborative", designed to strengthen protective and reduce risk factors among young adolescents. Baseline data was utilized from all 16 public middle and high schools located in two West Virginia counties in the United States during fall of 2019. Students from these counties represent a spectrum of diverse characteristics from families living in severe isolation/poverty to modest privilege/affluence [48].

\section{Procedure}

During the fall of 2019 survey data were collected by teachers under the supervision of a school contact agent that operated as a liaison to the research team. Upon review by West Virginia University Institutional Review Board (IRB), a requirement for informed consent by parents/caregivers was waived due to the benign nature of the study questions, confidentiality guarantee (no individually identifiable data was collected), and importance of very high response rates for community engagement purposes (IRB \# 1406345394A009). All accessible students enrolled in grades seven through twelve were surveyed. The aggregated sample consisted of 3395 respondents from all schools in two purposively selected counties (response rate $=80.4 \%$ ). One participating county is located in the Southern part of the state and the other in the central part. On the most recent Robert Wood Johnson County health rankings these counties were ranked in the bottom quarter out of the 55 counties in the state. Table 1 includes descriptive statistics for all study variables. 
Table 1 Descriptive Statistics

\begin{tabular}{|c|c|c|}
\hline$N=2351$ & $\begin{array}{l}\text { Younger group, grades 7-8 } \\
(n=1229)\end{array}$ & $\begin{array}{l}\text { Older group, grades } 9-10 \\
(n=1122)\end{array}$ \\
\hline & n (\%) & n (\%) \\
\hline \multicolumn{3}{|l|}{ Gender } \\
\hline Female & $596(48.5 \%)$ & $543(48.4 \%)$ \\
\hline Male & $602(49.0 \%)$ & $554(49.4 \%)$ \\
\hline \multicolumn{3}{|l|}{ Family Structure } \\
\hline Lives with both parents & $630(51.3 \%)$ & $558(49.7 \%)$ \\
\hline Other living arrangements & $599(48.7 \%)$ & $564(50.3 \%)$ \\
\hline Lifetime Drunkenness (Ever been drunk) & $103(10.0 \%)$ & $222(21.6 \%)$ \\
\hline Current Alcohol Use (Past 30 Days) & $65(6.4 \%)$ & $136(13.4 \%)$ \\
\hline Lifetime Cigarette Use (Ever Used) & $180(17.3 \%)$ & $255(24.5 \%)$ \\
\hline Current Cigarette Use (Past 30 Days) & $46(4.4 \%)$ & $96(9.2 \%)$ \\
\hline \multicolumn{3}{|l|}{ Race/Ethnicity } \\
\hline Asian & $17(1.4 \%)$ & $13(1.2 \%)$ \\
\hline White & $1116(90.8 \%)$ & 1037 (92.4\%) \\
\hline Black or African American & $60(4.9 \%)$ & $55(4.9 \%)$ \\
\hline Hispanic or Latino & $34(2.8 \%)$ & $29(2.6 \%)$ \\
\hline Native Hawaiian or Pacific Islander & $5(0.4 \%)$ & $5(0.5 \%)$ \\
\hline American Indian or Native American & $76(6.2 \%)$ & $51(4.5 \%)$ \\
\hline \multirow[t]{2}{*}{ Other } & $48(4.0 \%)$ & $27(2.4 \%)$ \\
\hline & Mean (SD) & Mean (SD) \\
\hline Parental Support (range 4.00-16.00) & $17.1(3.5)$ & $17.1(3.7)$ \\
\hline Parental Monitoring (range 5.00-20.00) & $13.7(2.5)$ & $13.6(2.7)$ \\
\hline Maternal Education (range 1.0-6.0) & $4.4(2.8)$ & $5.0(2.7)$ \\
\hline Relative Income (range 1.0-7.0) & $5.0(1.4)$ & $4.9(1.3)$ \\
\hline
\end{tabular}

\section{Measures}

Dependent variables

\section{Smoking status Lifetime smoking}

Students' smoking history was measured with a single question "How often have you smoked cigarettes in your lifetime?", with response categories ranging from $1=$ "Never" to 7="40 times or more". Responses were coded into a binary variable titled with $0=$ "No" and $1=$ "Yes".

\section{Current smoking}

Current cigarette smoking status was measured with a single question. "How much have you smoked cigarettes, on average, during the last 30 days?". Response categories ranged from $1=$ "Nothing" to $7=$ "More than 20 cigarettes per day". Responses were coded into a binary variable titled with $0=$ "No" and $1=$ "Yes".

Current alcohol use

Current alcohol use was assessed with four items that were assessed with the question "How often have you had a drink of alcohol of any kind in the past 30 days?" Response categories ranged from $1=$ "Never" to $7=" 40$ times or more". Responses were coded into a binary variable with $0=$ "No" and $1=$ "Yes".

Lifetime drunkenness

Adolescent drunkenness was assessed with the question "How often have you become drunk during your lifetime". Response categories ranged from $1=$ "Never" to $7=$ "40 times or more". Responses were coded into a binary variable with $0=$ "No" and $1=$ "Yes".

\section{Independent variables}

Parental support The Perceived Parental Support Scale (PPS), previously validated by Kristiánsson et al., [7] was used to assess parental support among respondents. The scale includes five items that were headed with the statement "How easy or hard would it be to receive the following from your parents/caregiver?": [1] Caring and warmth; [2] Discussions about personal affairs; [3] Advice about school; [4] Advice about other issues (projects) of yours; [5] Assistance with other things. Response categories ranged from $1=$ Very difficult to 
$4=$ Very easy. For univariate models, scores were summed to form a scale' total possible scores ranged from 5 to 20, with lower scores indicating lower levels of parental support. For the multivariate interaction models, scores were averaged $(\mathrm{m}=3.39)$ to form a scale $(\alpha=.91)$.

Parental monitoring Parental monitoring was assessed with four items used in previous studies $[49,50]$ pertaining to parental knowledge about their children's whereabouts and their friends: [1] My parents/caregivers know whom I am with in the evenings; [2] My parents/caregivers know where I am in the evenings; [3] My parents/ caregivers know my friends; [4] My parents/caregivers know the parents of my friends. Response categories ranged from 1="Applies very well to me" to 4="Applies very poorly to me". For univariate models, scores were reverse coded and summed to form a scale $(\alpha=.82)$. Total possible scores ranged from 4 to 16 , with lower scores indicating higher parental monitoring. For multivariate interaction models, scores were averaged to form a scale $(\mathrm{m}=3.39)$.

Gender Gender was measured with a single item: "How do you describe your gender?", with answer options $1=$ "Boy", 2 = "Girl", 3 = "Gender non-conforming", and 4= "Other (Please specify)". For the purposes of our analyses, gender was re-coded with $0=$ "Boys" and $1=$ "Girls", and 85 respondents that answered "other" or "non-conforming" were omitted.

Age group Age was dichotomized into two groups, signifying older and younger adolescents with grades 7-8 being classified as ' $0=$ Middle School-aged' and grades 9-10 classified as ' 1 = High School-aged'.

\section{Control variables}

Three variables, used in previous studies, [51, 52] were employed as proximal measures for socioeconomic status (SES). These include maternal education, family structure, and relative family income. Socioeconomic status has been associated with many adolescent health outcomes, including substance use [51-53].

Maternal education Similar to some previous studies, [53] maternal education was assessed with one item: "What is the highest level of schooling your mother has completed?", with answers ranging from $1=$ "I don't know/doesn't apply to me" to 6="Graduated from junior college or trade school".

Family structure Family structure was reported via one multiple-choice question pertaining to all people living in the student's household. For the purpose of our analyses we merged respondents into a dichotomized variable with 1 = "lives with both biological parents", and $0=$ "lives in other arrangements".

Relative income Relative income was measured with the question, "How well off financially do you think your family is in comparison to other families in your country?"; with answer options, reverse coded, ranging from $1=$ "Much worse off" to 7="Much better off".

\section{Statistical analyses}

Employing one-way Analysis of Variance (ANOVA) we began our analyses by testing the mean difference on the primary independent variables of interest, parental support and parental monitoring, first by stratifying the data by age and testing within gender, and then by stratifying the data by gender and testing within age groups. These results are portrayed in the beginning of the Results section. We then proceeded to run a series of binary logistic regression models to assess the multivariate relations and potential three-way and two-way interaction effects across primary independent variables and the four outcomes; lifetime cigarette smoking, current cigarette smoking, current alcohol use, and lifetime drunkenness, while controlling for SES. Due to multicollinearity issues inherent in interaction models, we reduced multicollinearity issues by centering all variables in the final models, which kept all Variance Inflation Factors in the acceptable range $(<2)$. Results are portrayed in odds ratios (OR) with $99 \%$ confidence intervals $(\mathrm{CI})$.

\section{Results}

Demographic information and descriptives are included in Table 1.

We began by running a correlational analysis which showed that there were no high correlations across key study variables. All correlations were less than .2, other than substance use practices with other substance use (which were not included in the same model. Further details are in Table 2, below).

Next, we tested for mean differences across parental support and parental monitoring by gender within the two age groups. For the younger group, 7-8th grade students, the mean score on parental support was $17.19(\mathrm{SD}=3.45)$ for boys and $17.23(\mathrm{SD}=3.32)$ for girls with a non-significant F-test for group differences $[F(1,1134)=0.40, p=.84]$. Parental monitoring scores within the same age group were 13.48 (SD = $2.56)$ for boys and $14.05(\mathrm{SD}=2.24)$ for girls which is significant at the 95\% level $[F(1,1147)=16.08, p<.01]$.

For the older group, 9-10th grade students, the mean score on parental support was $17.23(\mathrm{SD}=3.40)$ for boys and $17.01(\mathrm{SD}=3.84)$ for girls, also with a non-significant F-test for group differences 
Table 2 Bivariate Correlations

\begin{tabular}{|c|c|c|c|c|c|c|c|c|c|}
\hline & Gender & $\begin{array}{l}\text { Relative } \\
\text { Income }\end{array}$ & $\begin{array}{l}\text { Family } \\
\text { Structure }\end{array}$ & $\begin{array}{l}\text { Lifetime } \\
\text { Cigarettes }\end{array}$ & $\begin{array}{l}\text { Current } \\
\text { Cigarettes }\end{array}$ & $\begin{array}{l}\text { Lifetime } \\
\text { Drunkenness }\end{array}$ & $\begin{array}{l}\text { Current } \\
\text { Alcohol }\end{array}$ & $\begin{array}{l}\text { Parental } \\
\text { Monitoring }\end{array}$ & $\begin{array}{l}\text { Parental } \\
\text { Support }\end{array}$ \\
\hline Gender & . & $-0.06^{* *}$ & 0.00 & $-0.05^{* *}$ & $-0.05^{* *}$ & -0.03 & $-0.06^{* *}$ & $0.14^{* *}$ & 0.01 \\
\hline $\begin{array}{l}\text { Relative } \\
\text { Income }\end{array}$ & $-0.06^{* *}$ & . & $0.013^{* *}$ & $-0.12^{* *}$ & $-0.07^{* *}$ & $0.10^{* *}$ & $-0.04^{*}$ & $0.13^{* *}$ & $0.19^{* *}$ \\
\hline $\begin{array}{l}\text { Family } \\
\text { Structure }\end{array}$ & 0.00 & $0.013^{* *}$ & . & $-0.18^{* *}$ & $-0.11^{* *}$ & $-0.14^{* *}$ & $-0.07^{* *}$ & $0.14^{* *}$ & $0.20^{* *}$ \\
\hline $\begin{array}{l}\text { Lifetime } \\
\text { Cigarettes }\end{array}$ & $-0.05^{* *}$ & $-0.12^{* *}$ & $-0.18^{* *}$ & & $0.54^{* *}$ & $0.51^{* *}$ & $0.37^{* *}$ & $-0.20^{* *}$ & $-0.21^{* *}$ \\
\hline $\begin{array}{l}\text { Current } \\
\text { Cigarettes }\end{array}$ & $-0.05^{* *}$ & $-0.07^{* *}$ & $-0.11^{* *}$ & $0.54^{* *}$ & . & $0.42^{* *}$ & $0.41^{* *}$ & $-0.19^{* *}$ & $-0.16^{* *}$ \\
\hline $\begin{array}{l}\text { Lifetime } \\
\text { Drunkenness }\end{array}$ & -0.03 & $0.10^{* *}$ & $-0.14^{* *}$ & $0.51^{* *}$ & $0.42^{* *}$ & & $0.61^{* *}$ & $-0.21^{* *}$ & $-0.17^{* *}$ \\
\hline $\begin{array}{l}\text { Current } \\
\text { Alcohol }\end{array}$ & $-0.06^{* *}$ & $-0.04^{*}$ & $-0.07^{* *}$ & $0.37^{* *}$ & $0.41^{* *}$ & $0.61^{* *}$ & . & $-0.18^{* *}$ & $-0.12^{* *}$ \\
\hline $\begin{array}{l}\text { Parental } \\
\text { Monitoring }\end{array}$ & $0.14^{* *}$ & $0.13^{* *}$ & $0.14^{* *}$ & $-0.20^{* *}$ & $-0.19^{* *}$ & $-0.21^{* *}$ & $-0.18^{* *}$ & & $0.31^{* *}$ \\
\hline $\begin{array}{l}\text { Parental } \\
\text { Support }\end{array}$ & 0.01 & $0.19^{* *}$ & $0.20^{* *}$ & $-0.21^{* *}$ & $-0.16^{* *}$ & $-0.17^{* *}$ & $-0.12^{* *}$ & $0.31^{* *}$ & . \\
\hline
\end{tabular}

$[F(1,1074)=1.09, p=.30]$. Parental monitoring scores within the older age group were 13.31 ( $\mathrm{SD}=2.75)$ for boys and $13.83(\mathrm{SD}=2.63)$ for girls which is significant at the $95 \%$ level $[F(1,1063)=9.91, p=.02]$. Subsequent tests for mean differences by age group within gender revealed non-significant differences for boys on parental support $[F(1,1111)=0,06, \quad p=.82]$ and parental monitoring $[F(1,1111)=1.13, p=.29]$ as well as for girls on parental support $[F(1,097)=1.03, p=.31]$ and parental monitoring $[F(1,1099)=2.24, p=.14]$. Table 1 includes descriptive statistics for all study variables.

Frequency (percentage) or Mean (SD) reported.

Table 3 includes the results from the logistic regression models to assess the relations between the primary independent variables, parental monitoring and parental support, and all four outcome variables.

As shown, parental support and parental monitoring were significantly and negatively related to all outcome variables with ORs ranging from .91-.92 for parental support $(p<.05)$ and ORs ranging from .86-.89 for parental monitoring $(p<.05)$. Further, the odds of all four types of substance use, lifetime cigarette smoking, current cigarette smoking, current alcohol use, and lifetime drunkenness, increase with higher age group with ORs ranging from $1.45-2.61(p<.05)$.

Finally, we ran the four models testing for three-way interaction effects of Monitoring or Support with Gender and Grade as well as two-way interaction effects (see

Table 3 Binary Logistic Regression Models (Odds Ratios with 95\% Confidence Intervals)

\begin{tabular}{|c|c|c|c|c|}
\hline & \multicolumn{4}{|c|}{ Outcomes Variable for each Model } \\
\hline & $\begin{array}{l}\text { Lifetime } \\
\text { Cigarettes }\end{array}$ & $\begin{array}{l}\text { Current } \\
\text { Cigarettes }\end{array}$ & $\begin{array}{l}\text { Current } \\
\text { Alcohol }\end{array}$ & $\begin{array}{l}\text { Lifetime } \\
\text { Drunkenness }\end{array}$ \\
\hline $\begin{array}{l}\text { Age Group } \\
{[0=\text { younger, } 1=\text { older }]}\end{array}$ & $1.45^{*}[1.14,1.84]$ & $2.25^{*}[1.49,3.41]$ & $2.20^{*}[1.56,3.10]$ & $2.61^{*}[1.98,3.46]$ \\
\hline $\begin{array}{l}\text { Gender } \\
{[0=\text { boy, } 1=\text { girl }]}\end{array}$ & $1.00[0.79,1.27]$ & $1.05[0.72,1.54]$ & $0.68^{*}[0.49,0.94]$ & $0.93[0.71,1.20]$ \\
\hline Family Structure [0 = other, $1=$ both parents $]$ & $0.57^{*}[0.45,0.73]$ & $0.79[0.53,1.18]$ & $0.80[0.57,1.12]$ & $0.73^{*}[0.56,0.96]$ \\
\hline Maternal Education & $0.99[0.95,1.04]$ & $0.95[0.88,1.02]$ & $1.10^{*}[1.04,1.17]$ & $0.99[0.94,1.04]$ \\
\hline Relative Income & $0.88^{*}[0.80,0.96]$ & $0.94[0.81,1.08]$ & $1.02[0.90,1.15]$ & $0.89 *[0.80,0.98]$ \\
\hline Parental Support & $0.91 *[0.88,0.94]$ & $0.91 *[0.87,0.96]$ & $0.92^{*}[0.88,0.96]$ & $0.92^{*}[0.89,0.95]$ \\
\hline Parental Monitoring & $0.88^{*}[0.85,0.93]$ & $0.86^{*}[0.81,0.92]$ & $0.87^{*}[0.82,0.91]$ & $0.89 *[0.85,0.93]$ \\
\hline
\end{tabular}


Table 4 Binary Logistic Regression Models (Odds Ratios with 99\% Confidence Intervals) with Interaction Terms

\begin{tabular}{|c|c|c|c|c|}
\hline & Outcomes Varia & Model & & \\
\hline & $\begin{array}{l}\text { Lifetime } \\
\text { Cigarettes }\end{array}$ & $\begin{array}{l}\text { Current } \\
\text { Cigarettes }\end{array}$ & $\begin{array}{l}\text { Current } \\
\text { Alcohol }\end{array}$ & $\begin{array}{l}\text { Lifetime } \\
\text { Drunkenness }\end{array}$ \\
\hline $\begin{array}{l}\text { Age Group } \\
{[0=\text { younger, } 1=\text { older }]}\end{array}$ & $2.52^{*}[1.12,2.10]$ & $2.63^{*}[1.45,4.78]$ & $2.60^{*}[1.59,4.26]$ & $2.73^{*}[1.87,3.98]$ \\
\hline $\begin{array}{l}\text { Gender } \\
{[0=\text { boy, } 1=\text { girl }]}\end{array}$ & $0.97[0.71,1.33]$ & $1.05[0.61,1.79]$ & $0.71[0.46,1.11]$ & $0.91[0.64,1.28]$ \\
\hline $\begin{array}{l}\text { Family Structure } \\
{[0=\text { other, } 1=\text { both parents }]}\end{array}$ & $0.56^{*}[0.41,0.76]$ & $0.72[0.43,1.20]$ & $0.81[0.52,1.24]$ & $0.72^{*}[0.50,1.02]$ \\
\hline Maternal Education & $0.99[0.94,1.05]$ & $0.95[0.87,1.05]$ & $1.11^{*}[1.02,1.20]$ & $1.00[0.93,1.06]$ \\
\hline Relative Income & $0.87^{*}[0.78,0.98]$ & $0.93[0.77,1.12]$ & $1.00[0.85,1.17]$ & $0.88^{*}[0.77,1.00]$ \\
\hline Parental Support & $0.64^{*}[0.52,0.79]$ & $0.58^{*}[0.42,0.81]$ & $0.60^{*}[0.45,0.80]$ & $0.64^{*}[0.50,0.82]$ \\
\hline Parental Monitoring & $0.61^{*}[0.48,0.77]$ & $0.57^{*}[0.39,0.81]$ & $0.54^{*}[0.40,0.75]$ & $0.62^{*}[0.47,0.81]$ \\
\hline $\begin{array}{l}\text { Parental Support* } \\
\text { Age Group }\end{array}$ & $1.44[0.96,2.18]$ & $1.94 *[1.04,3.63]$ & $1.86^{*}[1.07,3.22]$ & $1.36[0.85,2.17]$ \\
\hline $\begin{array}{l}\text { Parental Support* } \\
\text { Gender }\end{array}$ & $0.77[0.51,1.17]$ & $0.96[0.52,1.75]$ & $0.90[0.52,1.54]$ & $0.83[0.52,1.33]$ \\
\hline $\begin{array}{l}\text { Parental Monitoring* } \\
\text { Age Group }\end{array}$ & $0.96[0.60,1.53]$ & $0.83[0.41,1.69]$ & $1.00[0.54,1.86]$ & $0.99[0.58,1.69]$ \\
\hline $\begin{array}{l}\text { Parental Monitoring* } \\
\text { Gender }\end{array}$ & $1.07[0.66,1.71]$ & $0.76[0.37,1.56]$ & $0.96[0.51,1.79]$ & $0.99[0.58,1.70]$ \\
\hline
\end{tabular}

Table 4). There were no significant three-way effects. Only two interaction effects were significant. Significant interaction relations were found for Parental Support and Age for current cigarette use $(\mathrm{OR}=1.94,99 \% \mathrm{CI}=$ 1.04-3.63) and current alcohol use $(\mathrm{OR}=1.86,99 \% \mathrm{CI}=$ 1.07-3.22). The main effect of parental monitoring was significantly associated with all substance use outcome variables. The main effect of parental support was significantly associated with both lifetime substance use outcomes.

\section{Discussion}

This investigation into gender and age-related differences in parental support and parental monitoring on alcohol and tobacco use revealed four important findings. First, at the bivariate level, girls reported more parental monitoring than boys irrespective of age-group, while no differences were observed for parental support by gender. This coincides with existing research given the differing socialization of boys and girls; girls are more closely monitored than boys. Further, no differences were observed for either parental support or parental monitoring by age-group within gender. In short, younger boys are not supported more or monitored more by their parents than older boys, and the same goes for girls.

Second, the initial multivariate analyses revealed both parental support and parental monitoring were found to be protective of substance use irrespective of age group and gender. That is, for both boys and girls in both the younger and older groups, greater levels of parental support and parental monitoring served to decrease the odds of cigarette smoking and alcohol use across all four alcohol and tobacco categories.

Third, we observed no gender differences between parental support and parental monitoring on all four outcome variables. In other words, the associations between parental support and parental monitoring on the four substance use outcomes were not different for boys or girls irrespective of age group.

Finally, we found a significant difference in the associations between parental support and three of four outcome variables by age group, with stronger associations for the older group. Put simply, increased parental support appears to be stronger protection for lifetime cigarette smoking, current cigarette smoking, and current alcohol use among older adolescents (9-10th graders) than when compared with the younger adolescents (7-8th graders) after taking account of parental monitoring and control variables. No such differences were observed for parental monitoring.

\section{Implications for Research and Practice}

While girls are monitored at higher levels than boys, regardless of age; parental monitoring does not appear to affect one gender over the other in terms of substance use outcomes. It is common for girls in the US and Europe to be monitored more closely than their male counterparts [54, 55]. However, this study shows that the extra monitoring experienced by girls in this population 
does not necessarily indicate a stronger protective factor against substance use. While girls are often monitored more closely than boys, it does not necessarily result in a stronger protective factor against substance use. These findings suggest monitoring girls more closely than boys appears unnecessary in terms of preventing adolescent substance use and abuse. Taken together, our findings indicate the importance of parental monitoring throughout adolescent development, regardless of a child's age or gender. It appears that monitoring can have a significant impact on adolescent onset of substance use. Thus, regardless of the expectation of substance use across age or gender, parents who are aware of where their children are and who they are with can have an impact on substance use initiation.

While gender differences were not observed in this study, a significant interaction effect was found for support by age group in three of four outcomes, favoring older participants. It has been well established that parental monitoring and parental support are protective factors against substance use outcomes among teens and adolescents, [1-3] and our study arrived at those conclusions as well. However, this study also found that parental support is an even stronger protective factor against substance use for older adolescents than it is for younger adolescents. This implies that as children mature, particularly from middle school to high school, parental emotional support may play an even bigger role in preventing substance use for the older youth compared to the younger ones. As further demonstrated in our models, with age comes a natural progression in the odds of substance use. This is to be expected given that opportunities to experiment with tobacco and alcohol likely increase with age and increased independence. Our findings demonstrate that the protective effect of parental support on adolescent experimentation with tobacco and alcohol is even greater as they move into high school, a period associated with more independence and opportunities to participate in risk behavior [56]. While parental monitoring has long been regarded as an important protective factor for adolescent substance use, $[1,10]$ our observation indicates that parental support may grow in importance in preventing substance use among this population. The importance of parental support as children age may be an important aspect to investigate in future studies.

\section{Strengths and limitations}

This study had some strengths. First, we employed a large sample which allowed us to confidently stratify results by age group and gender while retaining suitable statistical power. Second, the wide age range in the sample also allowed us to capture age differences and separate statistical tests for older and younger adolescents, and to do so separately for boys and girls. Our study also had several limitations. The sample population consisted exclusively of public school youth in two West Virginia counties, and may not be generalizable to the larger American population. Secondly, the cross-sectional nature of our data limits our ability to draw conclusions concerning cause and effect. Third and finally, all responses were self-reported and thus subject to recall bias.

\section{Conclusions and future directions}

This study reinforces the value of parental support and monitoring as effective strategies that help prevent and reduce adolescent substance use and abuse. Additionally, findings emphasize that, although a baseline level of consistent parental monitoring remains important throughout adolescence, increasing levels of parental support as young people grow older and become more independent seems to be protective for both genders. As such, ensuring parents understand how to provide effective support represents an essential component of primary prevention-based efforts to reduce adolescent substance use and abuse. Findings also suggest that - at least in terms of adolescent alcohol and tobacco use - parents may unnecessarily over-monitor young women's activities. However, it is difficult to definitively make this determination without additional research that accounts for all substances, and for the different types of parental monitoring and support offered to different genders.

Although this study provides important evidence related to the overall value of parental support and monitoring at different ages and by gender, it did not investigate the relative value of specific monitoring and support behaviors (i.e., emotional comfort vs. advice). Future studies designed to extend this line of inquiry could include the influence and relative value of specific parental support and monitoring strategies, especially those related to providing parental support at different ages. Doing so may represent an important next step in better understanding how to apply these primary prevention strategies in the most effective manner possible.

\section{Acknowledgements \\ Not applicable.}

\section{Authors' contributions}

RM, ALK, MJM and MLS authored the background literature review, as well as structured the conclusions and discussion. RM and ALK authored the methods section, and analyzed and interpreted the data and results. All authors were major contributors in writing the manuscript. All authors read and approved the final manuscript.

\section{Funding}

The Centers for Disease Control and Prevention (CDC) provided funding for this research under the Collaborative Agreements mechanism to WV Prevention Research Center at West Virginia University (Grant \# U48DP006391). The CDC had no role in the design of the study, data 
collection, analysis, or interpretation of data. All analyses and writing are the sole and mutual responsibility of the authors.

\section{Availability of data and materials}

The datasets generated and/or analyzed during the current study are not publicly available due co-utility and ownership by local schools and boards of education but are available from the corresponding author on reasonable request without school, county, or individual identifiers.

\section{Declarations}

\section{Ethics approval and consent to participate}

In compliance with the Declaration of Helsinki, parents/caregivers were informed about the study and offered to withdraw their children from the study via a mixture of take-home mail and emails from each participating school. The requirement for informed consent by parents/caregivers was waived due to the benign nature of the study questions, confidentiality guarantee (no individually identifiable data was collected), and importance of very high response rates for community engagement purposes. Adolescent participants were given the opportunity to voluntarily assent to study participation and informed that they could withdraw at any time without repercussions. All aspects of data collection protocols for this study were reviewed and approved by West Virginia University IRB (protocol \# 1406345394A009).

\section{Consent for publication}

Not applicable.

\section{Competing interests}

The authors declare that they have no competing interests.

\section{Author details}

${ }^{1}$ School of Public Health, West Virginia University, Morgantown, USA. ${ }^{2}$ Boise State University, Boise, USA.

\section{Received: 21 April 2021 Accepted: 20 October 2021}

Published online: 04 November 2021

\section{References}

1. Fay H, LaParo D, Shentu Y, Vasquez D, Welsh JW. Perceived parental knowledge and adolescent substance use outcomes. J Sch Health. 2020; https://doi.org/10.1111/josh.12933;90(9):711-7.

2. Gordon MS, Russell BS, Finan LJ. The influence of parental support and community belonging on socioeconomic status and adolescent substance use over time. Subst Use Misuse. 2020; https://doi.org/10.1080/10826084.201 9.1654513:55(1):23-36.

3. Kuntsche $S$, Kuntsche E. Parent-based interventions for preventing or reducing adolescent substance use - a systematic literature review. Clin Psychol Rev. 2016; https://doi.org/10.1016/j.cpr.2016.02.004;45:89-101.

4. Micalizzi L, Sokolovsky AW, Janssen T, Jackson KM. Parental social support and sources of knowledge interact to predict children's externalizing behavior over time. J Youth Adolesc. 2019; https://doi.org/10.1007/s10964018-0969-4;48(3):484-94

5. Rusby JC, Light JM, Crowley R, Westling E. Influence of parent-youth relationship, parental monitoring, and parent substance use on adolescent substance use onset. J Fam Psychol. 2018; https://doi.org/10.1037/fam00003 50;32(3):310-20.

6. Barnes GM, Reifman AS, Farrell MP, Dintcheff BA. The effects of parenting on the development of adolescent alcohol misuse: a six-wave latent growth model. J Marriage Fam. 2000; https://doi.org/10.1111/j.1741-3737.2000.001 75.x;62(1):175-86.

7. Kristjánsson AL, Sigfusdottir ID, Karlsson T, Allegrante JP. The perceived parental support (PPS) scale: validity and reliability in the 2006 youth in Europe substance use prevention survey. Child Indic Res. 2011; https://doi. org/10.1007/s12187-010-9095-x;4(3):515-28.

8. Janssen LHC, Elzinga BM, Verkuil B, Hillegers MHJ, Keijsers L. The link between parental support and adolescent negative mood in daily life: between-person heterogeneity in within-person processes. J Youth Adolesc. 2021; https://doi.org/10.1007/s10964-020-01323-w;50(2):271-85.

9. Wills TA, Okamoto SK, Knight R, Pagano I. Parental support, parentadolescent conflict, and substance use of native Hawaiian and other pacific islander youth: ethnic differences in stress-buffering and vulnerability effects. Asian Am J Psychol. 2019; https://doi.org/10.1037/aap0000139;10(3):218-26.

10. Borca G, Rabaglietti E, Roggero A, Keller P, Haak E, Begotti T. Personal values as a mediator of relations between perceived parental support and control and youth substance use. Subst Use Misuse. 2017; https://doi.org/10.1080/1 0826084.2017.1293103;52(12):1589-601.

11. Rudi J, Dworkin J. Is technology-mediated parental monitoring related to adolescent substance use? Subst Use Misuse. 2018; https://doi.org/10.1080/1 0826084.2017.1408653;53(8):1331-41.

12. Stice E, Barrera M, Chassin L. Relation of parental support and control to adolescents' externalizing symptomatology and substance use: a longitudinal examination of curvilinear effects. J Abnorm Child Psychol. 1993; https://doi.org/10.1007/BF00916446;21(6):609-29.

13. Dumont IP, Olson AL. Primary care, depression, and anxiety: exploring somatic and emotional predictors of mental health status in adolescents. J Am Board Fam Med. 2012;25(3):291-9. https://doi.org/10.3122/jabfm.2012. 03.110056 .

14. Serafini K, Stewart DG, Wendt DC, Donovan DM. Perceived parental support and adolescent motivation for substance use change: a preliminary investigation. Addict Res Theory. 2018; https://doi.org/10.1080/16066359.201 7.1342819;26(3):187-92.

15. Yang GL, Zhang AD, Yu Y, Liu H, Long FY, Yan J. Drug use and its associated factors among money boys in Hunan province, China. Public Health. 2016; https://doi.org/10.1016/j.puhe.2016.06.005;140:213-20.

16. Vazsonyi AT. Parent-adolescent relations and problem behaviors: Hungary, the Netherlands, Switzerland, and the United States. Marriage Fam Rev. 2008;35(3-4):161-87. https://doi.org/10.1300/J002v35n03_09.

17. Wills TA, Resko JA, Ainette MG, Mendoza D. Role of parent support and peer support in adolescent substance use: a test of mediated effects. Psychol Addict Behav. 2004;18(2):122-34. https://doi.org/10.1037/0893-164 X.18.2.122.

18. Field T. Violence and touch deprivation in adolescents. Adolescence. 2002; 37(148):735-49.

19. Abar CC, Clark G, Koban K. The long-term impact of family routines and parental knowledge on alcohol use and health behaviors: results from a 14 year follow-up. J Child Fam Stud. 2017; https://doi.org/10.1007/s10826-0170752-2;26(9):2495-504

20. Kerr M, Stattin H. What parents know, how they know it, and several forms of adolescent adjustment: further support for a reinterpretation of monitoring. Dev Psychol. 2000;36(3):366-80. https://doi.org/10.1037/0012-1 649.36.3.366.

21. Kristjánsson AL, James JE, Allegrante JP, Sigfusdottir ID, Helgason AR. Adolescent substance use, parental monitoring, and leisure-time activities: 12-year outcomes of primary prevention in Iceland. Prev Med. 2010; https:// doi.org/10.1016/j.ypmed.2010.05.001;51(2):168-71.

22. Ryan SM, Jorm AF, Lubman DI. Parenting factors associated with reduced adolescent alcohol use: a systematic review of longitudinal studies. Australian \& New Zealand Journal of Psychiatry. 2010; https://doi.org/10.1 080/00048674.2010.501759:44(9):774-83.

23. Muchiri BW, dos Santos MML. Family management risk and protective factors for adolescent substance use in South Africa. Subst Abuse Treat Prev Policy. 2018; https://doi.org/10.1186/s13011-018-0163-4;13(1):24.

24. Hair EC, Moore KA, Garrett SB, Ling T, Cleveland K. The continued importance of quality parent-adolescent relationships during late adolescence. J Res Adolesc. 2008;18(1):187-200. https://doi.org/10.1111/j.1 532-7795.2008.00556.x

25. Ellis DA, Podolski CL, Frey M, Naar-King S, Wang B, Moltz K. The role of parental monitoring in adolescent health outcomes: impact on regimen adherence in youth with type 1 diabetes. J Pediatr Psychol. 2007; https:// doi.org/10.1093/jpepsy/jsm009;32(8):907-17.

26. Yabiku ST, Marsiglia FF, Kulis S, Parsai MB, Becerra D, Del-Colle M. Parental monitoring and changes in substance use among Latino/a and non-Latino/ a preadolescents in the southwest. Subst Use Misuse. 2010; https://doi.org/1 0.3109/10826081003728256;45(14):2524-50.

27. Hurley E, Dietrich T, Rundle-Thiele S. A systematic review of parent based programs to prevent or reduce alcohol consumption in adolescents. BMC Public Health. 2019. https://doi.org/10.1186/s12889-019-7733-x;19(1):1451.

28. Mustanski B, Swann G, Newcomb ME, Prachand N. Effects of parental monitoring and knowledge on substance use and HIV risk behaviors among young men who have sex with men: results from three studies. AIDS Behav. 2017. https://doi.org/10.1007/s10461-017-1761-2;21(7):2046-58. 
29. Allen ML, Garcia-Huidobro D, Porta C, Curran D, Patel R, Miller J, et al. Effective parenting interventions to reduce youth substance use: a systematic review. Pediatrics. 2016. https://doi.org/10.1542/peds.2015-4425; 138(2):e20154425.

30. Basu S, Zuo X, Lou C, Acharya R, Lundgren R. Learning to be gendered: gender socialization in early adolescence among urban poor in Delhi, India, and Shanghai, China. The Journal of adolescent health: Official publication of the Society for Adolescent Medicine. 2017; https://doi.org/10.1016/j.ja dohealth.2017.03.012:61(4):S24-9.

31. Cook RE, Nielson MG, Martin CL, DeLay D. Early adolescent gender development: the differential effects of felt pressure from parents, peers, and the self. J Youth Adolesc. 2019; https://doi.org/10.1007/s10964-01901122-y;48(10):1912-23.

32. Mmari K, Blum RW, Atnafou R, Chilet E, de Meyer S, El-Gibaly O, et al. Exploration of gender norms and socialization among early adolescents: the use of qualitative methods for the global early adolescent study. J Adolesc Health. 2017; https://doi.org/10.1016/j.jadohealth.2017.07.006;61(4):S12-8.

33. Ram U, Strohschein L, Gaur K. Gender socialization: differences between male and female youth in India and associations with mental health. International Journal of Population Research. 2014; https://doi.org/10.1155/2 014/357145;2014:1-11.

34. Amin A, Kågesten A, Adebayo E, Chandra-Mouli V. Addressing gender socialization and masculinity norms among adolescent boys: policy and programmatic implications. J Adolesc Health. 2018; https://doi.org/10.1016/j. jadohealth.2017.06.022;62(3):S3-5.

35. Rivera A, Scholar J. Traditional masculinity: a review of toxicity rooted in social norms and gender socialization. Adv Nurs Sci. 2020; https://doi.org/ 0.1097/ANS.0000000000000284:43(1):E1-E10.

36. Kristjánsson AL, Sigfúsdóttir ID. The role of parental support, parental monitoring, and time spent with parents in adolescent academic achievement in Iceland: a structural model of gender differences. Scand J Educ Res. 2009:53(5):481-96. https://doi.org/10.1080/00313830903180786.

37. Abar CC, Jackson KM, Wood M. Reciprocal relations between perceived parental knowledge and adolescent substance use and delinquency: the moderating role of parent-teen relationship quality. Dev Psychol. 2014; https://doi.org/10.1037/a0037463;50(9):2176-87.

38. Becerra D, Castillo J. Culturally protective parenting practices against substance use among adolescents in Mexico. J Subst Abuse. 2011; https:// doi.org/10.3109/14659891.2010.518199;16(2):136-49.

39. Nelson KM, Carey KB, Scott-Sheldon LAJ, Eckert TL, Park A, Vanable PA, et al, Gender differences in relations among perceived family characteristics and risky health behaviors in urban adolescents. Ann Behav Med. 2017; https:// doi.org/10.1007/s12160-016-9865-x;51(3):416-22.

40. Choquet M, Hassler C, Morin D, Falissard B, Chau N. Perceived parenting styles and tobacco, alcohol and cannabis use among French adolescents: gender and family structure differentials. Alcohol Alcohol. 2008; https://doi. org/10.1093/alcalc/agm060;43(1):73-80.

41. Griffin KW, Botvin GJ, Scheier LM, Diaz T, Miller NL. Parenting practices as predictors of substance use, delinquency, and aggression among urban minority youth: moderating effects of family structure and gender. Psychol Addict Behav. 2000; https://doi.org/10.1037/0893-164X.14.2.174;14(2):174-84.

42. Magid V, Moreland AD. The role of substance use initiation in adolescent development of subsequent substance-related problems. J Child Adolesc Subst Abuse. 2014; https://doi.org/10.1080/1067828X.2012.748595;23(2):7886.

43. DeWit DJ, Adlaf EM, Offord DR, Ogborne AC. Age at first alcohol use: a risk factor for the development of alcohol disorders. Am J Psychiatry. 2000; https://doi-org.www.libproxy.wvu.edu/10.1176/appi.ajp.157.5.745;157(5):74550.

44. Bryant AL, Schulenberg PMO, Bachman JG, Johnston LD. How academic achievement, attitudes, and behaviors relate to the course of substance use during adolescence: a 6-year, multiwave national longitudinal study. J Res Adolesc. 2003; https://doi.org/10.1111/1532-7795.1303005;13(3):361-97.

45. Abio A, Sezirahiga J, Davis L, Wilson M. Substance use and sociodemographic correlates among adolescents in a low-income sub Saharan setting. J Inj Violence Res. 2020; https://doi.org/10.5249/jivr.v12i1.11 95;12(1):21-7.

46. Peltzer K, Pengpid S. Cannabis and amphetamine use and socio-ecological (proximal and distal) factors among school-going adolescents in four countries in the Caribbean and four countries in South America. Int J Adolesc Med Health. 2019; https://doi.org/10.1515/ijamh-2018-0030;33(1).
47. Handren LM, Donaldson CD, Crano WD. Adolescent alcohol use: protective and predictive parent, peer, and self-related factors. Prev Sci. 2016; https:// doi.org/10.1007/s11121-016-0695-7;17(7):862-71.

48. Appalachian Regional Commission. Poverty rates in appalachia, 2013-2017. 2017. https://www.arc.gov/map/poverty-rates-in-appalachia-2013-2017/.

49. Kristjánsson AL, Sigfusdottir ID, Allegrante JP, Helgason AR. Parental divorce and adolescent cigarette smoking and alcohol use: assessing the importance of family conflict. Acta Paediatr. 2009; https://doi.org/10.1111/j.1 651-2227.2008.01133.x;98(3):537-42.

50. Kristjánsson AL, Sigfusdottir ID, Thorlindsson T, Mann MJ, Sigfusson J, Allegrante JP. Population trends in smoking, alcohol use and primary prevention variables among adolescents in Iceland, 1997-2014. Addiction. 2016; https://doi.org/10.1111/add.13248;111(4):645-52.

51. Conger RD, Conger KJ, Martin MJ. Socioeconomic status, family processes, and individual development. J Marriage Fam. 2010; https://doi.org/10.1111/ j.1741-3737.2010.00725.x;72(3):685-704.

52. Cowan CD, Hauser RM, Kominski RA, Levin HM, Lucas SR, Morgan SL. Improving the measurement of socioeconomic status for the national assessment of educational progress: a theoretical foundation. 2012; Retrieved from https://nces.ed.gov/nationsreportcard/pdf/researchcenter/ socioeconomic_factors.pdf

53. Kuruczova D, Klanova J, Jarkovsky J, Pikhart H, Bienertova-Vasku J. Socioeconomic characteristics, family structure and trajectories of children's psychosocial problems in a period of social transition. PLoS One. 2020; https://doi.org/10.1371/journal.pone.0234074;15(6):e0234074.

54. Janssen HJ, Eichelsheim VI, Deković M, Bruinsma GJN. Sex differences in longitudinal pathways from parenting to delinquency. Eur J Crim Policy Res. 2017; https://doi.org/10.1007/s10610-017-9350-5;23(4):503-21.

55. Worthen MGF. Gender differences in parent-child bonding: implications for understanding the gender gap in delinquency. J Crim Just. 2011; https://doi. org/10.1080/0735648X.2011.554744;34(1):3-23.

56. Blankenstein NE, Telzer EH, Do KT, Van Duijvenvoorde AC, Crone EA. Behavioral and neural pathways supporting the development of prosocial and risk-taking behavior across adolescence. Child Dev. 2020; https://doi. org/10.1111/cdev.13292.

\section{Publisher's Note}

Springer Nature remains neutral with regard to jurisdictional claims in published maps and institutional affiliations.
Ready to submit your research? Choose BMC and benefit from:
- fast, convenient online submission
- thorough peer review by experienced researchers in your field
- rapid publication on acceptance
- support for research data, including large and complex data types
- gold Open Access which fosters wider collaboration and increased citations
- maximum visibility for your research: over $100 \mathrm{M}$ website views per year
At BMC, research is always in progress.
Learn more biomedcentral.com/submissions 